\title{
Nitrophenols Reduction in the Benzene Adiabatic Nitration Process
}

\author{
Paulo A. Quadros,* J osé A. A. M. Castro, ${ }^{\dagger}$ and Cristina M. S. G. Baptista
}

GEPSI-PSE Group, Department of Chemical Engineering, University of Coimbra, Pólo II, Pinhal de Marrocos, 3030-290 Coimbra, Portugal

\begin{abstract}
The benzene adiabatic nitration process has been carried out in a pilot plant to enable the study of this reaction under relevant industrial operating conditions, aiming to increase the reaction conversion and selectivity by reducing the nitrophenols. The influence of relevant operating parameters such as the reaction temperature, benzene-to-nitric acid molar feed ratio $\left(\mathrm{F}_{\mathrm{B}} / \mathrm{F}_{\mathrm{N}}\right)$, and stirring speed was studied. The operation ranges covered were as follows: reaction temperature, $80-135^{\circ} \mathrm{C} ; \mathrm{F}_{\mathrm{B}} / \mathrm{F}_{\mathrm{N}}, 0.96-1.15$; stirring speed, 360-1700 rpm. The residence time and the sulfuric acid concentration were fixed at $2 \mathrm{~min}$ and $68 \mathrm{wt} \%$, respectively. The production of cleaner mononitrobenzene (MNB) requires lower nitration temperatures; higher $F_{B} / F_{N}$ ratios than in current industrial practice; and high stirring speeds, allowing the interfacial area in this liquid-liquid mixture to be increased and the decrease in temperature to be compensated. The results reported here highlight the rel evance of combining operating parameters to improve the performance of the reactor. In this study, it was possible to accomplish the same MNB production with a significant reduction in nitrophenols concentration. This work presents results that might be useful for conventional industrial benzene adiabatic nitration plants, to improve the prevention of pollution in this process and allow competitiveness with new plants in fulfilment of environmental law requirements.
\end{abstract}

\section{Introduction}

Pollution prevention in industrial chemical processes can be a relevant contribution toward sustainable devel opment and is fully encouraged by the increasing legal constraints and limits imposed on pollutant concentrations in industrial effluents. ${ }^{1}$ The optimization of industrial chemical processes by improving reaction conversion and selectivity, and therefore reducing unwanted byproducts, can have significant economic and environmental impacts. The formation of byproducts represents a loss in the final product and requires additional equipment and separation stages to purify the product and effluent streams, which can lead to consi derable added economic costs. ${ }^{2}$

At the industrial scale, the production of mononitrobenzene (MNB) through benzene nitration with nitric and sulfuric acid (mixed acid) is usually performed in continuous mode. The urge to improve the contact between the two liquid phases, overcoming masstransfer limitations in this simultaneous mass transfer with chemical reaction process, gave origin to the development of different industrial processes. ${ }^{3-6}$ Guenkel and Maloney presented a configuration in which mechanical stirrers are not used because the main reactor contains jet impingement el ements. ${ }^{7}$ Burns and Ramshaw suggested a capillary microreactor to carry out the benzene nitration. ${ }^{8,9}$ Both of these works try to solve some of the usual limitations, namely, the masstransfer resistances, to achieve better selectivity and conversion. Neverthel ess, conventional industrial adiabatic nitration plants are running, and it is important to optimize the operating conditions and introduce significant rearrangements to comply with limits imposed by recent environmental laws. This process

\footnotetext{
* E-mail: quadros3@eq.uc.pt. Tel.: + 351239798782. Fax: + 351239798703.

$\dagger$ Deceased.
}

optimization has to be carried out carefully to allow for the economic feasibility of the process and enable older facilities to stay competitive under narrower environmental constraints.

The nitration of benzene is a heterogeneous liquidliquid reaction that uses sulfuric acid as the catalyst, producing MNB and forming nitrophenols (NPS) as the main byproducts, namely, di- and trinitrophenols (DNP and TNP). In the industrial process, the weight percentage of NPs formed ranges from 0.1 to $0.5 \%$ of the total MNB produced. However, because the MNB annual production is estimated to be over 1.5 million tonnes in Europe alone, ${ }^{10}$ these small percentages represent large amounts of toxic byproducts per year. Market demand requires these byproducts to be removed from the final MNB product, and the usual disposal procedures consist of incineration or deposition very deep in the subsoil, with the known risks associated with these measures.

The benzene nitration reaction mechanism has been established, 11,12 and according to this mechanism, it is the nitronium ion $\left(\mathrm{NO}_{2}{ }^{+}\right)$, produced by the dissociation of the nitric acid and catalyzed by the sulfuric acid, that nitrates the benzene. It is important to note that, if the nitration reaction is extremely favored, the benzene can be dinitrated to produce dinitrobenzene (DNB); however, throughout our experiments DNB was not detected. The formation of DNB usually takes place when higher reaction temperatures, residence times, or sulfuric acid strengths are employed. 8,13

In the literature, the information on NP formation is scarce, and the mechanism is not fully settled. Burns and Ramshaw ${ }^{8}$ suggested that, in the benzene nitration process, NP formation is partly due to mass-transfer limitations between the organic and aqueous phases. According to these authors, ${ }^{8}$ the undissociated nitric acid that transfers into the organic phase oxidizes the benzene to produce phenol, the precursor of NPs. This mass transfer is enhanced by the concentration of 


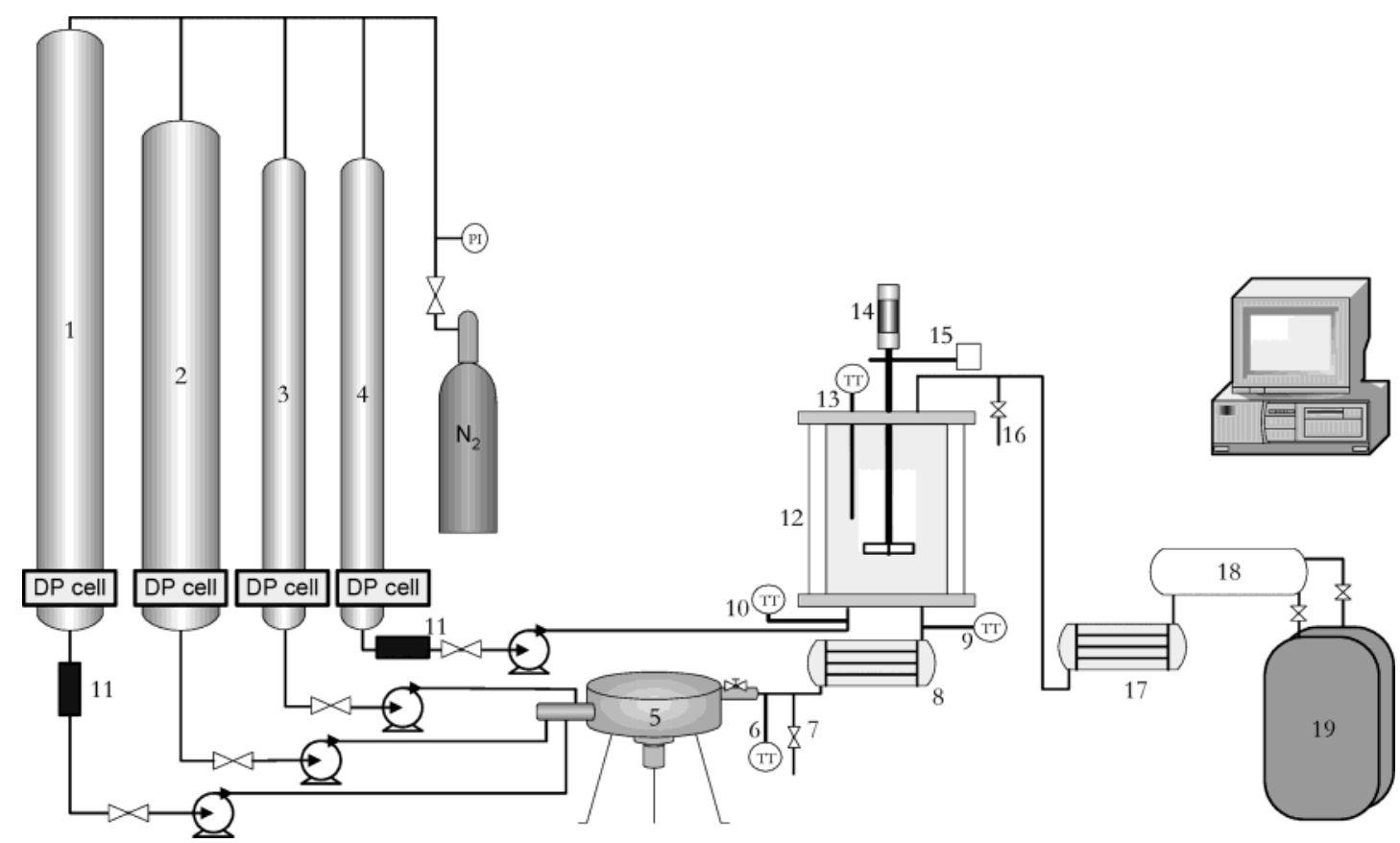

Figure 1. Pilot-plant scheme: 1 , sulfuric acid tank; 2, water tank; 3, nitric acid tank; 4, benzene tank; 5, mixed-acid reactor; 6 , mixedacid temperature sensor; 7, mixed-acid sample collecting valve; 8 , mixed-acid heat exchanger; 9, mixed-acid feed to the main reactor temperature sensor; 10, benzene feed temperature sensor; 11, pneumatic cutoff security valves; 12 , main reactor; 13 , reactor temperature sensor; 14, pneumatic driver; 15, digital tachometer; 16, reaction sample collecting valve; 17, heat exchanger; 18 , decanter and heat exchanger; 19, effluent collecting reservoir.

nitrobenzene, ${ }^{14}$ the main reaction product that, once formed, transfers into the organic phase and extracts the nitric acid in an anhydrous form, as the solubility of the other components of the mixed acid is very low. ${ }^{14,15}$ The anhydrous nitric acid is a powerful oxidizing agent, ${ }^{15}$ capable of oxidizing benzene into phenol. Once the phenol is formed, it is rapidly transferred into the acid phase and nitrated. ${ }^{5}$ In this reaction mechanism, the first step is phenol sulfonation that leads to the phenolsulfonic acid, which is then nitrated by replacing the sulfonic groups by nitronium ones, 16 producing the NPs that then transfer into the organic phase. This reaction is much faster than benzene nitration and should occur at the interface. Several authors have suggested that some undesired reactions or even small part of the nitration reaction might occur in the organic phase. ${ }^{15,17,18}$ Nevertheless, the maximum rate of nitration in the organic phase is many orders of magnitude less than the rate in the aqueous phase and can be neglected. ${ }^{18,19}$

The side reactions occur simultaneously with the nitration of benzene by the nitronium ion $\left(\mathrm{NO}_{2}{ }^{+}\right)$. Therefore, the ultimate goal of a benzene nitration process is to produce the nitronium ion solution that will nitrate the aromatic substrate while leaving no nitric acid available to oxidize the aromatic reactant and produce unwanted byproducts. The composition of the mixed acid might be decisive in converting most of the nitric acid to $\mathrm{NO}_{2}{ }^{+}, 5,7$ Guenkel and Maloney state that reducing the nitric acid content in the mixed acid to a level lower than 3\% and working within a specific range of sulfuric acid concentrations enabled a major reduction of TNP to trace levels. ${ }^{5,7}$ Nevertheless, the levels of DNP produced are still in the range of those obtained with prior approaches, ${ }^{4,5}$ confirming that some of the benzene is still oxidized to produce DNP. Depending on the sulfuric acid strength, the nitration reaction can be fast, occurring at the interface, or slower, taking place in the bulk of the aqueous phase. ${ }^{20-22}$ In experiments con- ducted previously, the intermediate regime prevailed, and the reaction took place in the film and in the bulk of the aqueous phase. ${ }^{23}$

Different approaches are being followed in recent nitration processes, which use nitronium ion salts such as $\mathrm{NO}_{2} \mathrm{BF}_{4}$ and $\mathrm{NO}_{2} \mathrm{PF}_{6}$ instead of the usual mixed acids, to achieve a higher selectivity. ${ }^{1}$ The use of anhydrous nitrogen pentoxide in nitrations has been implemented with success and is leading to the development of different techniques to manufacture this pure compound free from nitric acid and at lower costs. ${ }^{24-26}$

The aim of this work is to contribute to the understanding of the influence of the main operating parameters on the formation of NPs in the actual operating benzene adiabatic nitration process. The results re ported here should be useful for the implementation of a pollution prevention strategy in operating conventional plants, once scale-up drawbacks are overcome. At a pilot-plant scale, the continuous adiabatic benzene nitration process is reproduced under industrially relevant operating conditions, to enable the identification of the parameters that most strongly influence the process and the secondary reactions, to optimize the MNB production in a cleaner way, enhancing the economic and environmental benefits.

\section{Pilot Plant Design and Operation}

To carry out this study, a pilot plant was built and improved through experimentation, with special attention paid to the materials used. The experimental procedure and the analytical techniques were developed and thoroughly tested. Additionally, the chemical reactants involved and the operating conditions to be tested required special consideration to ensure safety.

2.1. Pilot-Plant Description. The pilot plant illustrated in Figure 1 was built to allow the continuous benzene adiabatic nitration process under industrial conditions to be reproduced. The reactant feed tanks, 
made of stainless steel, are identified by numbers 1-4. The aqueous reactants are fed to the mixed-acid reactor (5), made of Teflon, through FMI metering feed pumps to produce the mixed acid, which passes through a glass/ Teflon heat exchanger (8) before entering the main reactor (12). The benzene is fed directly into the main reactor where the nitration reaction is performed. The reactor is made of Teflon/glass with an approximate volume of $1 \mathrm{~L}$ and is fully described elsewhere. ${ }^{27} \mathrm{An}$ Atlas Copco pneumatic drive (14) allows for the use of different stirring speeds, which are registered by a digital tachometer (15) and stored in the computer. The stirrer used is a two-paddle impeller, made of Teflon and tantalum, whose dimensions are given elsewhere. ${ }^{27}$ Omega PT100 (6, 9, 10, and 13) temperature sensors allow the temperature to be measured in different positions in the pilot plant and these data to be transmitted to the data acquisition system. After the main reactor, the effluent stream goes to a glass/Teflon heat exchanger (17) and a glass separator (18), where it is cooled before being collected in polypropylene reservoirs (19). Swagelok PFA needl e valves (7 and 16) allow for the collection of samples from the mixed-acid reactor and from the main reactor. Safety procedures were implemented to allow the reaction to be stopped al most instantaneously by cutting off reactant feeding and agitation. These include two pneumatic Whitey cutoff security valves (11) installed to all ow the benzene and sulfuric acid feeds to be stopped from the control desk. Moreover, the pneumatic driver and every pump connected to the tanks can be turned off at the control desk.

2.2. Running an Experiment. The startup of the pilot plant is a complex task and follows a strict procedure to ensure the safety of the operator and the quality of the results. First, the sulfuric acid and water pumps are turned on and set to the flow rates that produce the desired sulfuric acid concentration. The heat of dilution of the sulfuric acid is significant, and this first step must be carried out carefully. I mmediately afterward, the nitric acid feed to the mixed-acid reactor is started to produce the mixed acid with a previously established concentration and temperature. The heat exchanger installed between the two reactors allows for the control of the mixed-acid temperature before it enters the main reactor. After stabilization of the temperature and flow-rate profiles, the benzene is fed into the main reactor, where it reacts with the mixed acid. This stirred reactor operates adiabatically, and once a constant temperature and a steady state are reached, samples of the reacting mixture and of the mixed acid are collected through valves 16 and 7 in Figure 1. It is important to cool the samples very rapidly to stop the reaction al most instantaneously. Therefore, these samples are collected into gl ass flasks previously filled with inert nitrogen and with chilled 4-mmdiameter glass beads to increase the heat-exchange surface and improve the cooling. The flasks are then placed in an ice and water bath to guarantee that they reach room temperature very rapidly. Once this whole procedure is accomplished, the stirring speed is changed to a new set point so that a new steady state can be reached. The process stabilization usually takes $3-5$ residence times, which can be followed and confirmed by the temperature profiles registered on-line in the pilot-plant computer. In the Results and Discussion
Table 1. Ranges of Operating Conditions Tested in the Experimental Runs

\begin{tabular}{ll}
\hline \multicolumn{1}{c}{ parameter } & \multicolumn{1}{c}{ range } \\
\hline reaction temperature $(\mathrm{T})$ & $80-135^{\circ} \mathrm{C}$ \\
mixed-acid temperature & $80-103{ }^{\circ} \mathrm{C}$ \\
stirring speed $(\mathrm{N})$ & $360-1700 \mathrm{rpm}$ \\
hold-up fraction $(\epsilon)$ & $0.13-0.18$ \\
molar ratio between benzene and nitric acid $\left(\mathrm{F}_{\mathrm{B}} / \mathrm{F}_{\mathrm{N}}\right)$ & $0.96-1.15$ \\
residence time $(\tau)$ & $\sim 2 \mathrm{~min}$ \\
sulfuric acid concentration (free from nitric acid) & $\sim 68 \mathrm{wt} \%$ \\
nitric acid content in the mixed acid produced & $\sim 5 \mathrm{wt} \%$
\end{tabular}

section below, on-line temperature profiles (Figure 2) are presented for a representative experimental run.

The operating conditions used in the experimental runs reproduce the industrial operating conditions of a conventional adiabatic nitration process and are summarized in Table 1. Some important operating parameters were fixed according to the industrial conditions. Sulfuric acid and water are mixed to produce an inlet sulfuric acid concentration of $68 \%$ (by weight), free from nitric acid, which is added to the nitric acid at $60 \%$, producing a final mixed acid with a nitric acid concentration of approximately $5 \%$. The residence time was fixed at $2 \mathrm{~min}$ in every run. The data presented in this work were collected during 12 runs that enabled 66 different steady states to be attained. The mixed-acid temperature ranged from 80 to $103^{\circ} \mathrm{C}$. Along each run, the stirring speed was incremented, and in the whole set of experiments, agitation ranged between 360 and $1700 \mathrm{rpm}$. The mixed-acid temperature and stirring speed influence the reaction temperature, which ranged from 80 to $135{ }^{\circ} \mathrm{C}$. Two other inlet parameters were changed between runs: the molar feed ratio between benzene and nitric acid $\left(\mathrm{F}_{\mathrm{B}} / \mathrm{F}_{\mathrm{N}}\right)$ was varied in the range $0.96-1.15$ and the hold-up fraction $(\epsilon)$ ranged between 0.13 and 0.18 .

In this pilot plant, the duration of the operation is limited by the reactant-tank capacities. The startup process of the pilot plant can require 10-25 min, and for the particular residence time and operating conditions used, the operation lasts for 60-80 min.

2.3. Analytical Techniques. The reaction samples collected during the experimental runs were al lowed to decant, and the two phases were separated. The aque ous phase was titrated with a $1 \mathrm{M}$ sodium hydroxide solution to determine the total acidity and with iron sulfate to calculate the nitric acid content. The same analytical procedure was used to analyze the mixedacid samples. The organic phase was prepared for gas chromatography (GC) and liquid chromatography (HPLC) analysis. The GC analyses allowed the concentrations of MNB and benzene in the reaction sample to be evaluated. These samples were prepared in methanol and analyzed in a silica gel DB-1 J \& W column, with a specific temperature program using a 9001 Tremetrics gas chromatograph. Toluene was used as the internal standard to allow for accurate quantification.

The HPLC analyses allowed determination of the samples' NP content, namely, DNP and TNP, and were carried out according to the following procedure: First, $1 \mathrm{~mL}$ of the organic phase was mixed with $2 \mathrm{~mL}$ of $1 \mathrm{M}$ $\mathrm{NaOH}$ to obtain an alkaline extraction of the NPs into the aqueous phase. This mixture was vigorously shaken and then centrifuged for complete separation of the two phases. Once this process had been completed, $1 \mathrm{~mL}$ of the aqueous phase, which now contained the NPs, was collected and introduced into a $20-\mathrm{mL}$ balloon flask, where it was neutralized with phosphoric acid. Theflask 


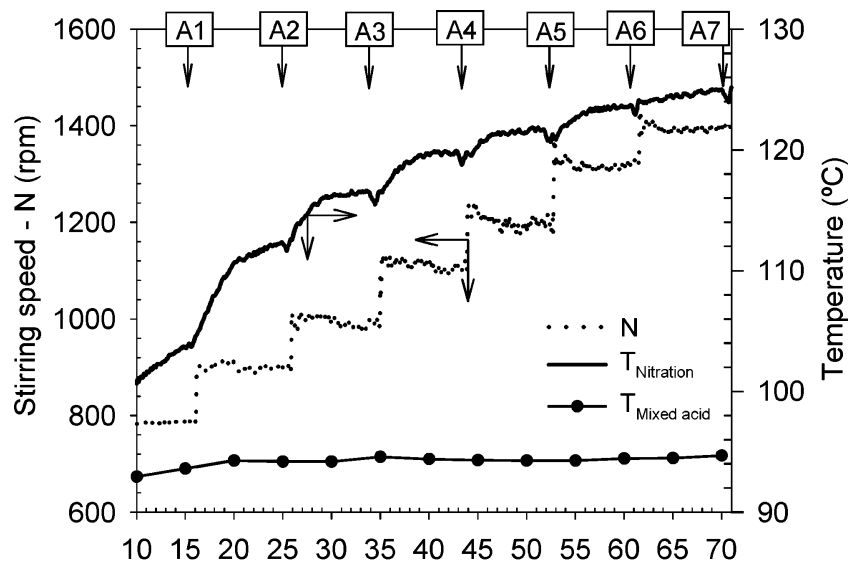

Time $(\min )$

Figure 2. On-line profiles of stirring speed, reaction temperature, and mixed-acid temperature for an experimental run.

volume was filled with $1 \mathrm{~mL}$ of phenol and ultrapure water for HPLC analysis. The phenol was added to perform as an internal standard in the HPLC quantification, which improves its accuracy. The elluent used was a mixture of methanol and ultrapure water in a 1:1 proportion with 1 vol \% of PIC A reagent from Waters. A K nauer HPLC pump and a UV detector were used at a wavelength of $360 \mathrm{~nm}$, with a Kromasil 100 C18 Teknokroma column at a flow rate of $1.1 \mathrm{~mL} \mathrm{~min}^{-1}$ at $35^{\circ} \mathrm{C}$.

Tests showed that, after the nitration process, the samples did not contain phenol, not even mononitrophenol, indicating that, once the phenol had been formed, it reacted almost instantaneously to produce DNP and TNP. This enables the use of phenol as the internal standard in the HPLC procedure.

\section{Results and Discussion}

The design of experiments was carefully carried out so that the data collected would enable a better understanding of the benzene nitration process through the identification of the different mechanisms involved. The pilot plant was operated continuously, and in each run, several steady states could be reached by changing input variables such as the stirring speed or flow rates. Between runs, flow rates and inlet temperatures were changed, and the range of operating conditions tested is summarized in Table 1 . The experimental runs were assisted and followed by computer, which allowed for the monitoring of important parameters such as flow rates, temperatures, stirring speed, residence time, and reactant levels in the feeding tanks. Moreover, it was with the aid of the computer that the operator confirmed that steady-state operation had been reached and set the new parameter values. An example of the monitored profiles for the stirring speed and the reaction and mixed-acid temperatures is presented in Figure 2. These profiles refer to an experimental run where seven different steady states were reached. The corresponding monitored reactant flow rates are plotted in Figure 3. In these figures, the pilot plant startup process is not represented, and therefore, the first data points refer to a running time of $10 \mathrm{~min}$. In both figures, one can determine that the stirring speed was the operating parameter altered and that, as it was augmented, an increase in reaction temperature was registered. The nitration temperature profile was used to control the

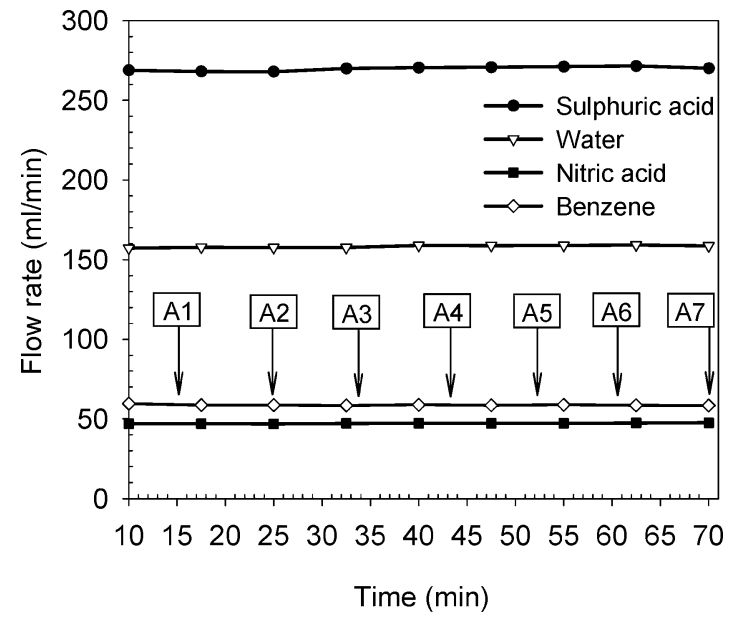

Figure 3. On-line monitoring profiles of the reactant inlet flow rates for an experimental run.

steady-state regime. Once the temperature stabilized, a steady state had been reached, and samples of the reacting mixture and of the mixed acid were collected. Then, a new set point for the stirring speed was selected, and the cycle was repeated until a new steady state had been reached. In Figures 2 and 3, the sample collecting times are identified by $A n, n=1-7$, each corresponding to a given steady state. The dependence of the reaction temperature on stirring speed is due to the nature of the nitration process under study, which is a masstransfer-limited and highly exothermic heterogeneous reaction. Increasing the stirring speed will increase the effective interfacial area in the reactor, ${ }^{27}$ which will promote the benzene mass transfer from the organic phase into the aqueous phase, where it will react with heat rel ease. For the range of operating conditions used, this reaction can be characterized as being masstransfer- and kinetically controlled, in an intermediate regime between slow and fast reaction, depending on the effective interfacial area available. ${ }^{23}$

In the present work, two main objectives were at stake: to increase both the MNB production and the selectivity of the process by reducing the unwanted nitrophenols in the final product.

3.1. Nitration Temperature. In industrial plants that run this adiabatic nitration process, the influence of temperature on NP formation is known, and this knowledge has enabled improvements in production and/or sel ectivity. The industrial process uses temperatures in the range of $130-140^{\circ} \mathrm{C}$. Several experiments were conducted in the pilot plant in the temperature range of $80-135^{\circ} \mathrm{C}$, wider than that used in industrial practice, in an attempt to obtain a full pattern for the influence of temperature on NP formation. To enable a comparative analysis, the concentrations of DNP and TNP in the outlet stream are plotted in Figure 4. These data correspond to the 66 steady states reached during experiments and show that NP formation is related to temperature. It is obvious that, in the whole temperature range, the amount of DNP produced largely exceeded the amount of TNP. Below $85^{\circ} \mathrm{C}$, TNP, also known as picric acid, was not formed. Traces of TNP were detected as the nitration temperature increased, but its concentration became significant only in the higher temperature range $\left(\mathrm{T}>110^{\circ} \mathrm{C}\right)$. Nevertheless, DNP was al ways detected, even at low process temperatures, and its concentration increased steadily with temperature, as shown in Figure 4. 


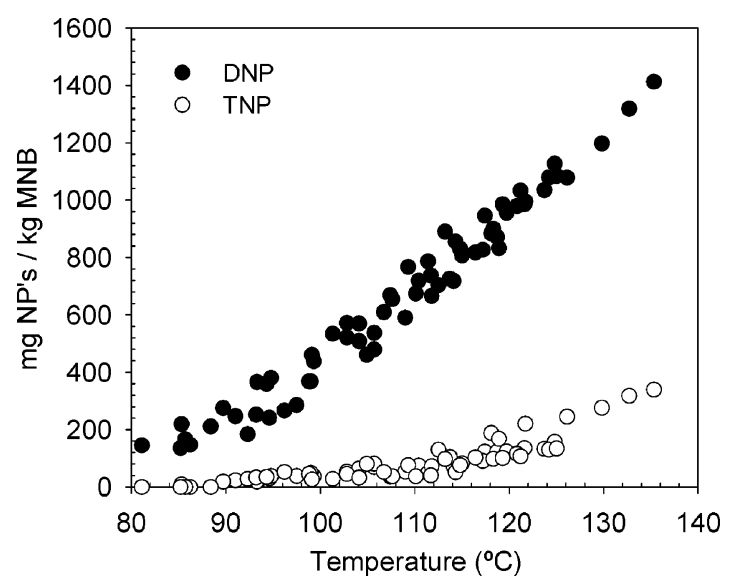

Figure 4. Experimental values for DNP and TNP formation versus reaction temperature for several experimental runs.

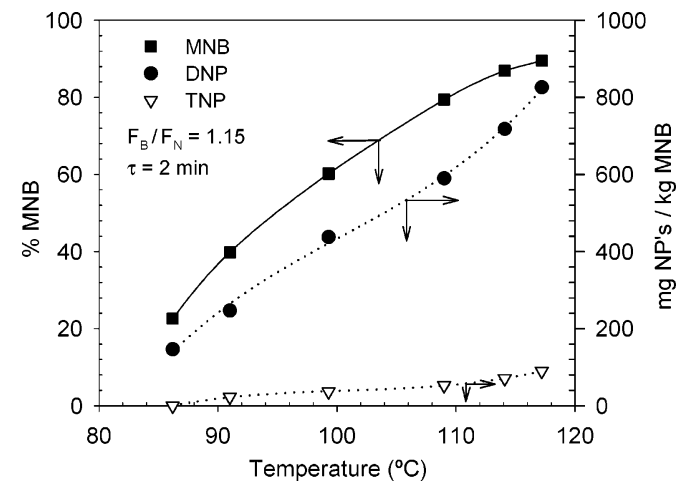

Figure 5. MNB, DNP, and TNP concentrations as functions of reaction temperature for a particular run.

This information is relevant but cannot be dissociated from the main industrial process goal, which is MNB production. Therefore, in Figure 5, the organic-phase weight percentage of MNB in the outlet stream is also plotted for a particular experimental run. The experimental data in Figure 5 show clearly that the influence of temperature is not restricted to NP formation, but is also relevant for MNB production.

The same trend of the influence of temperature on NP formation shown in Figures 4 and 5 was found by Urbanski ${ }^{16}$ in a study on the nitration of phenol. This author concluded that, in the presence of sulfuric acid, phenol produces phenoldi(tri)sulfonic acids that are nitrated to form DNP and TNP. According to the conditions tested by U rbanski, 16 if low temperatures are used, phenolsulfonic acid will be formed from phenol, and then mononitrophenol will be obtained. Phenoldisulfonic acid is formed in the $90-100{ }^{\circ} \mathrm{C}$ temperature range, and for a higher temperature, phenoltrisulfonic acid would be obtained. Our experimental data follow the same trend as the Urbanski results, namely, the increase in TNP formation with temperature.

The pilot-plant results presented in Figures 4 and 5 confirm that the temperature is an important parameter in NP formation, but variables such as stirring speed, molar feed ratio between benzene and nitric acid $\left(F_{B} / F_{N}\right)$, sulfuric acid concentration or even residence time might also be relevant. In this work, the sulfuric acid concentration and the residence time were fixed, and the influence of the other parameters was investigated.

3.2. $\mathbf{F}_{\mathbf{B}} / \mathbf{F}_{\mathbf{N}} \mathbf{R}$ atio. To evaluate the influence of the inlet $F_{B} / F_{N}$ ratio on the composition of the effluent
Table 2. Results Obtained for Different Sets of Operating Conditions: Influence of $\mathbf{F}_{\mathrm{B}} / \mathbf{F}_{\mathbf{N}}$

\begin{tabular}{cccrccc}
\hline set & $\begin{array}{c}\mathrm{T}_{\text {Nitration }}\left({ }^{\circ} \mathrm{C}\right) \\
\mathrm{F}_{\mathrm{B}} / \mathrm{F}_{\mathrm{N}}\end{array}$ & $\begin{array}{c}\mathrm{N} \\
(\mathrm{rpm})\end{array}$ & $\% \mathrm{MNB}$ & $\begin{array}{c}\mathrm{DNP}(\mathrm{mg} / \\
\mathrm{kg} \text { of MNB })\end{array}$ & $\begin{array}{c}\mathrm{TNP}(\mathrm{mg} / \\
\mathrm{kg} \text { of MNB })\end{array}$ \\
\hline 1 & 118.1 & 0.96 & 798 & 73.67 & 896 & 191 \\
2 & 118.9 & 1.07 & 809 & 74.80 & 853 & 172 \\
3 & 118.7 & 1.11 & 800 & 80.96 & 896 & 127 \\
4 & 118.3 & 1.09 & 1108 & 84.07 & 887 & 96
\end{tabular}

stream, several experiments were carried out in which this ratio was changed while the stirring speed and the temperature in the reactor remained the same. These correspond to some of the 66 steady states achieved, and attention is focused here on three of these sets of operating conditions and effluent compositions summarized in Table 2 . In sets $1-3$, an increase in $F_{B} / F_{N}$ ratio (from 0.96 to 1.11 ) improves the MNB percentage in the reactor by $9.9 \%$, which is accompanied by constancy in the DNP concentration and a remarkable $33.5 \%$ decrease in the weight of TNP formed. These results also show that, at a temperature lower than the range used in industry, there is room to reduce TNP formation whileimproving MNB production and process selectivity.

It is our understanding that, by increasing the concentration of benzene, its mass transfer to the aqueous phase can be improved, which will lead to a higher MNB production. Nevertheless, a higher $F_{B} / F_{N}$ ratio will lead to a lower $M N B$ concentration in the organic phase, lowering the solubility of anhydrous nitric acid in this phase. ${ }^{14}$ Moreover, the amount nitric acid available in the reacting mixture is lower, and this will regulate its transfer to the organic phase where, according to Burns and Ramshaw, ${ }^{8}$ it would oxidize the benzene to form phenol. We believe that this is the limiting step to NP formation because, once phenol is produced, it is al most instantaneously transferred into the aqueous phase and quickly nitrated. This is corroborated by the HPLC analyses of the reacting samples collected, which, as already reported, do not detect phenol or even mononitrophenol. Furthermore, a decrease in NP concentration with increasing $\mathrm{F}_{\mathrm{B}} / \mathrm{F}_{\mathrm{N}}$ ratio is confirmed by the experimental data in Table 2.

To fully support the conclusion that NPs are obtained from phenol and not from MNB, some confirmation experiments were carried out batchwise. At $100{ }^{\circ} \mathrm{C}$ and using a small 100-mL stirred batch reactor, nitration reactions were carried out using the same mixed acid as in the pilot reactor. In the first set of experiments, benzene was used, and the final mixture contained DNP and TNP. In the second set, benzene was replaced by $M N B$, and when the reaction products were analyzed, no traces of NPs were found. This confirms that MNB does not lead to NPs and, for certain, that they are produced in side reactions such as benzene oxidation to phenol. Therefore, to achieve an improved sel ectivity of the process, a faster production of MNB is better because it will not give rise to NPS.

It is worth pointing out that, in industrial adiabatic nitration plants, a benzene excess in the range of $6-8 \%$ is used. Guenkel and co-workers ${ }^{5}$ suggested a wider range, and therefore, the $\mathrm{F}_{\mathrm{B}} / \mathrm{F}_{\mathrm{N}}$ ratios tested in the pilot plant cover a wider range from a $4 \%$ excess of nitric acid to a $15 \%$ excess of benzene in the reactor inlet stream. The results of these experiments confirm the advantages of using an excess of benzene in the inlet $\mathrm{F}_{\mathrm{B}} / \mathrm{F}_{\mathrm{N}}$ molar 
Ind. Eng. Chem. Res., Vol. 43, No. 15, 2004

Table 3. Results Obtained for Different Sets of Operating Conditions - Influence of Stirring Speed

\begin{tabular}{cccccccrr}
\hline set & $\begin{array}{c}\mathrm{T}_{\text {Mixed acid }} \\
\left({ }^{\circ} \mathrm{C}\right)\end{array}$ & $\begin{array}{c}\mathrm{T}_{\text {Nitration }} \\
\left({ }^{\circ} \mathrm{C}\right)\end{array}$ & $\mathrm{F}_{\mathrm{B}} / \mathrm{F}_{\mathrm{N}}$ & $\begin{array}{c}\mathrm{N} \\
(\mathrm{rpm})\end{array}$ & $\% \mathrm{MNB}$ & $\begin{array}{c}\mathrm{DNP}(\mathrm{mg} / \\
\mathrm{kg} \text { of MNB })\end{array}$ & $\begin{array}{c}\text { TNP }(\mathrm{mg} / \\
\mathrm{kg} \text { of MNB) }\end{array}$ & $\begin{array}{c}\text { total NPs }(\mathrm{mg} / \\
\mathrm{kg} \text { of MNB) }\end{array}$ \\
\hline 5 & 102.7 & 126.1 & 1.07 & 1005 & 81.54 & 1092 & 248 & 1340 \\
6 & 95.0 & 124.8 & 1.07 & 1393 & 87.59 & 1129 & 157 & 1286 \\
7 & 92.8 & 125.0 & 1.09 & 1700 & 91.10 & 1007 & 133 & 1140
\end{tabular}

ratio and provide new information on performance improvements that can be obtained by increasing this ratio.

3.3. Stirring Speed. The effective interfacial area between the two liquid phases, which is intimately related to the stirring speed used, as shown in Quadros and Baptista, ${ }^{27}$ is considered to be another important parameter that contributes to the selectivity of this heterogeneous nitration process. An increase in the stirring speed, and therefore in the interfacial area between the two liquid phases, increases benzene mass transfer and chemical reaction. Because this mass transfer is enhanced, it is expected that an increase in the stirring speed will lead to the production of more MNB with less NPs.

In set 4 of Table 2 , the same operating conditions as the former sets were used, except for the stirring speed, which was increased. The $\mathrm{F}_{\mathrm{B}} / \mathrm{F}_{\mathrm{N}}$ ratio was settled between the values in sets 2 and 3 , and it can be observed that the increase in the stirring speed causes a significant improvement in MNB production. Regarding the NP formation, the DNP concentration remains the same, but the TNP concentration is reduced. We can confirm that, as expected, by increasing the stirring speed, we favor MNB formation and reduce the TNP concentration, improving the selectivity of the process, as required. Comparing sets 1 and 4, it is outstanding that a $50 \%$ reduction of TNP formation and a $14 \%$ increase in MNB production were achieved by increasing both the stirring speed and the $\mathrm{F}_{\mathrm{B}} / \mathrm{F}_{\mathrm{N}}$ molar ratio, with the process temperature kept constant.

In industrial plants, to achieve higher productions, temperatures exceeding the values tested in sets 1-4 are used. Therefore, some of the operating conditions were selected so that steady states with higher nitration temperatures were reached. The results obtained are summarized in Table 3. At nearly the same temperature and $F_{B} / F_{N}$ ratio (1.07), increasing the stirring speed (sets 5 and 6 ) gives rise to an increase in MNB and a decrease in TNP. Working now at higher temperatures, these results confirm the previous ones in sets $2-4$ achieved by improving the contact between the two phases. Comparing now sets 5 and 6 with set 7 , where the $F_{B} /$ $\mathrm{F}_{\mathrm{N}}$ ratio was slightly augmented and the stirring speed was considerably increased, we find that the MNB production improved again with a reduction in NP production. These sets at higher temperature reinforce the information obtained so far. This is also in full agreement with the results of Burns and Ramshaw. 8,9 When carrying out these reactions in capillary reactors, these authors showed that the smaller the reactor diameter, and hence the diffusion path, the lower the amount of NPs produced. In our tests, the reduction in NP concentration is a consequence of a shorter diffusion path when the drops become smaller.

Another relevant observation is that an increase in stirring speed allows the introduction of the mixed acid in the main reactor at a lower temperature without interfering with the reaction temperature, as shown in Table 3. This lower inlet temperature is compensated by the heat released, which increases proportionally to

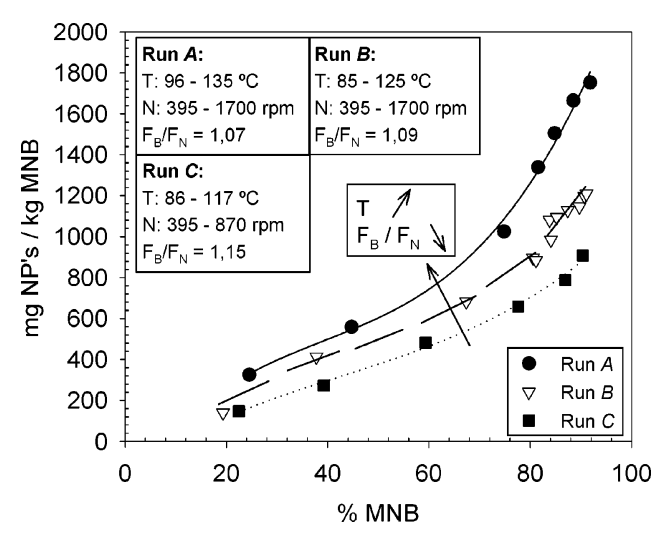

Figure 6. NP formation as a function of MNB production for different runs.

the extent of reaction, because of the increase in interfacial area between the two reacting phases. This feature can lead to significant energy benefits in an industrial plant.

3.4. Global Process Analysis. It has been reported in this study that increasing the stirring speed will result in an increase in the MNB concentration in the outlet stream but will also produce an increase in reaction temperature. On the other hand, this temperature increase will raise the NP formation, which is not desirable. Therefore, an increase in the stirring speed should only be implemented if the reaction temperature is kept unchanged. To achieve this, a lower mixed-acid temperature can be used, because the reaction heat released will increase with interfacial area, leading to the same reaction temperature, as shown in Table 3.

To further study the influence of operating conditions on cleaner MNB production, some of the runs were carried out using wider ranges of parameters. The main conclusions of this work are summarized in Figure 6 , as well as the achievements in the combination of the main operating variables. The results plotted in Figure 6 confirm that the same MNB production can be achieved with different NP concentrations. In run A, a lower $\mathrm{F}_{\mathrm{B}} / \mathrm{F}_{\mathrm{N}}$ ratio and higher temperatures were used, and the NPs formed were always in greater amount than for runs B and C. In fact, it is possible to show that, in run $C$, when a $15 \%$ excess of benzene in the inlet stream was used, the same maximum weight percentage of MNB in the outlet stream was reached as in the other runs, but with a reduction in temperature, $117{ }^{\circ} \mathrm{C}$, and in stirring speed, $870 \mathrm{rpm}$, and a remarkable decrease in NPs formed.

Comparing runs $\mathrm{A}$ and $\mathrm{C}$, the maximum MNB percentage was obtained with a $50 \%$ reduction in NPs, and this was achieved with a simultaneous significant improvement in power consumption, as the stirring speed is also reduced by $50 \%$. The experimental data pl otted in Figure 6 also bring evidence to the rel evance of the nitration temperature on NP formation. It is noticeable that the differences between NP formation among the three runs increase with the extent of nitration which, because of inlet parameters, corresponds to different temperature rises. 
In this pilot plant, the nitration is performed in one continuous stirred tank reactor, and it is also important to note that, by increasing the inlet $\mathrm{F}_{\mathrm{B}} / \mathrm{F}_{\mathrm{N}}$ ratio, it is possible to achieve a $90 \%$ conversion of benzene into MNB at a maximum temperature of only $117{ }^{\circ} \mathrm{C}$. In industrial plants, this process is often carried out in a series of 3-4 CSTRs to attain higher benzene conversions and compl ete consumption of nitric acid, enabling the recycling of the sulfuric acid. ${ }^{4}$ To increase the $\mathrm{F}_{\mathrm{B}} /$ $\mathrm{F}_{\mathrm{N}}$ ratio in each reactor, an alternative procedure could be implemented: a distributed feed of nitric acid. Instead of feeding all of the required nitric acid at the inlet of the first reactor in the series, it would be fed to every reactor al ong the series, according to the expected nitric acid consumption. A lower nitric acid concentration in each reactor would diminish its transfer into the organic phase, where it oxidizes benzene into phenol, and would reduce the NPs in the final product. This would be in full agreement with studies ${ }^{5,7}$ that recommend a concentration of nitric acid lower than 3\% to achieve a reduction in TNP formation. Although we value this suggestion, it has not been confirmed through experimentation, so it should be carefully tested before implementation.

In this work, attention has been mainly focused on the reaction vessel as the unit where the reactions occur. However, if none of the reactants is exhausted in the reactor, the main and side reactions can also occur in the connection pipes and separation stages. In a global process optimization, this feature must be considered. If static mixers are inserted in the connection pipes between reactors to increase the interfacial area and improve mixing, the desired reaction will be favored. In the final separation stages, where mixing is not used and the separation process can take some time, the main reaction almost stops, and the side reactions continue. In conventional plants, the separations are carried out in liquid-liquid decanters, but modern units use centrifuges to shorten the time required for the separation and reduce the chance of occurrence of side reaction in the nitration process. ${ }^{1}$

This concern about the contact time between phases when the reactant conversion is not complete means that it is considered relevant to the byproduct formation, but not to MNB production. Some extra experiments carried out in the pilot plant, but not reported here, confirmed that, for the same inlet conditions, when 4and 6-min residence times were used, the TNP concentration rose and approached the DNP values, without significant improvements in the MNB production.

This analysis based on experimental observations allows one to conclude that different sets of operating conditions can be used to obtain an improved quality in MNB manufacture. In future work, special attention will be paid to the mixed-acid composition to promote the formation of a nitronium ion solution. Therefore, higher sulfuric acid strengths and lower nitric acid contents ( $<3 \%$ ), instead of the $5 \%$ used in conventional processes and in these experiments, will be tested. According to the literature, this will improve the selectivity and significantly reduce the total amount of NPs produced, particularly the TNP. 5,7 Different reaction temperatures and residence times will also be studied.

\section{Conclusions}

The main goal of our work was to identify the best operating conditions for the optimization of the benzene continuous adiabatic nitration process through maximization of the process selectivity. Several experimental runs were conducted in a pilot plant built for this study, which allowed for the reproduction, at a pilot scale, of the industrial reaction process and for the testing of the influence of some important parameters. The resi dence time and the mixed-acid strength were fixed, enabling the temperature, the molar feed ratio between benzene and nitric acid $\left(\mathrm{F}_{\mathrm{B}} / \mathrm{F}_{\mathrm{N}}\right)$, and the stirring speed to be identified as the most influent parameters. The influence of these parameters was tested, and the results show that increases in the $\mathrm{F}_{\mathrm{B}} / \mathrm{F}_{\mathrm{N}}$ ratio and in the stirring speed augment the interfacial area available in the liquid-liquid mixture and therefore the MNB production, reducing NP formation. Experiments show that an increase in the reaction temperature can produce an increase in the MNB production, which usually is not followed by an increase in selectivity, as temperature will also augment NP formation.

A combination of several operating parameters is essential to achieve process optimization. It is advisable that an increase in the stirring speed and in the excess of benzene in the feed be combined with a reduction on reaction temperature. This can be achieved through a decrease of the mixed-acid inlet temperature, leading to an increase in the MNB production and selectivity. Results show that, once MNB is formed, it will not lead to phenol or NPs. These findings reinforce the advantages of processing the nitration of benzene as rapidly as possible, not allowing the nitric acid to transfer into the organic phase where it can oxidize the benzene into phenol. Once phenol is formed, it is impossible to stop its nitration leading to NP formation.

Recent environmental regulations restrict to part-perbillion levels the allowable concentrations of some of these byproducts in wastewaters. In industry, in-line process measures to reduce these undesired compounds are more effective and usually less expensive than an end-of-line treatment process, such as wet air oxidation, catalytic treatment, or carbon adsorption. ${ }^{1}$

The economic and environmental viability of some older industrial facilities can be improved by optimizing the operating conditions, which can be reinforced with the introduction of some new equipment, such as static mixers or jet impingement el ements and new separation processes. These improvements can significantly increase the feasibility of the running adiabatic processes, making them competitive with newly implemented manufacturing processes.

\section{Acknowledgment}

Financial support from Fundação para a Ciência e Tecnol ogia (FCT) for Ph.D. Grant SF RH/BD/1266/2000 and from Quimigal S.A., Portugal, is gratefully acknowledged. We also acknowledge the assistance in the experimental work of Engineers Alzira Vilaboa, Catarina Viana, and Raquel Costa. This work is dedicated to the memory of Professor J osé Almiro e Castro.

\section{Notation}

DNB $=$ dinitrobenzene

DNP $=$ dinitrophenol

$\mathrm{F}_{\mathrm{B}} / \mathrm{F}_{\mathrm{N}}=$ molar feed flow rate ratio between benzene and nitric acid

$\mathrm{MNB}=$ mononitrobenzene

$\mathrm{N}=$ stirring speed, $\mathrm{rpm}$ 
NPs $=$ nitrophenols

$\mathrm{T}=$ temperature, ${ }^{\circ} \mathrm{C}$

TNP = trinitrophenol

\section{Greek Letters}

$\epsilon=$ hold-up fraction of the dispersed phase

$\tau=$ residence time, $\min$

\section{Literature Cited}

(1) Albright, L. F.; Carr, R. V. C.; Schmitt, R. J . Nitration: An overview of recent developments and processes. In Nitration: Recent Laboratorial and Industrial Developments; Carr, R. V., Schmitt, R. J ., Albright, L. F., Eds.; ACS Symposium Series; American Chemical Society: Washington, DC, 1996; pp 1-9.

(2) Hanson, C.; Kaghazchi, T.; Pratt, M. W. T. Side reactions during aromatic nitration. In Industrial and Laboratorial Nitrations; Albright, L. F., Hanson, C., Eds.; ACS Symposium Series; American Chemical Society: Washington, DC, 1976; pp 132-155.

(3) Castner, J . B. Nitration of organic compounds. U.S. Patent 2,256,999, 1941 .

(4) Alexanderson, V.; Trecek, J .; Vanderwaart, C. Continuous adiabatic process for the mononitration of benzene. U.S. Patent 4,091,042, 1978.

(5) Guenkel, A.; Rae, J .; Hauptmann, E. Nitration process. U.S. Patent 5,313, 009, 1994

(6) Brereton, C.; Guenkel, A. Nitration process. U.S. Patent 5,963, 878, 1999.

(7) Guenkel, A. A.; Maloney, T. W. Recent advances in the technol ogy of mononitrobenzene manufacture. In Nitration: Recent Laboratorial and Industrial Developments; Carr, R. V., Schmitt, R. J ., Albright, L. F., Eds.; ACS Symposium Series; American Chemical Society: Washington, DC, 1996; pp 223-233.

(8) Burns, J. R.; Ramshaw, C. Development of a microreactor for chemical production. Trans. Inst. Chem. Eng. A 1999, 77, 206211.

(9) Burns, J . R.; Ramshaw, C. A microreactor for the nitration of benzene and toluene. Chem. Eng. Commun. 2002, 189 (12), 1611-1628.

(10) Nitrobenzene. In Chemical Economics Handbook; SRI International: Menlo Park, CA, 1997.

(11) Hughes, E. D.; Ingold, C. K.; Reed, R. I. Kinetics and mechanisms of aromatic nitration. Part II. Nitration by the nitronium ion, $\mathrm{NO}_{2}{ }^{+}$, derived from nitric acid. J . Chem. Soc. 1950 2400-2415.

(12) Olah, G. A.; Malhotra, R.; Narang, S. C. NitrationMethods and Mechanisms; VCH Publishers: New York, 1989.

(13) Alexanderson, V.; Trecek, J .; Vanderwaart, C. Adiabatic process for nitration of nitratable aromatic compounds. U.S. Patent 4,021,498, 1977

(14) Schiefferle, D. F.; Hanson, C.; Albright, L. F. Heteroge neous nitration of benzene. In Industrial and Laboratorial Nitra- tions; Albright, L. F., Hanson, C., Eds.; ACS Symposium Series; American Chemical Society: Washington, DC, 1976; pp 176-189.

(15) Albright, L. F.; Schiefferle, D. F.; Hanson, C. Reactions occurring in the organic phase during aromatic nitrations. J . Appl . Chem. Biotechnol. 1976, 26, 522-525.

(16) Urbanski, T. Chemistry and Technology of Explosives; Pergamon Press: Oxford, U.K., 1990; Vol. 1.

(17) Barduhn, A. J .; Kobe, K. A. Toluene nitration kinetics. Ind. Eng. Chem. 1956, 48 (8), 1305-1315.

(18) Giles, J.; Hanson, C.; Ismail, H. A. M. A model for rate of nitration of toluene under heterogeneous conditions. I I Industrial and Laboratorial Nitrations; Albright, L. F., Hanson, C., Eds.; ACS Symposium Series; American Chemical Society: Washington, DC, 1976; pp 190-209.

(19) Cox, P. R.; Strachan, A. N. Two-phase nitration of clorobenzene. Chem. Eng. Sci. 1971, 26, 1013-1018.

(20) Cox, P. R.; Strachan, A. N. Two-phase nitration of toluene Part II. Chem. Eng. J . 1972, 4, 253-261.

(21) Zaldivar, J. M.; Molga, E.; Alós, M. A.; Hernández, H.; Westerterp, K. R. Aromatic nitrations by mixed acid. Slow liquidliquid reaction regime. Chem. Eng. Process. 1995, 34, 543-559.

(22) Zaldivar, J. M.; Molga, E.; Alós, M. A.; Hernández, H.; Westerterp, K. R. Aromatic nitrations by mixed acid. Fast liquidliquid reaction regime. Chem. Eng. Process. 1996, 35 (2), 91-105.

(23) Quadros, P. A.; Oliveira, N. M. C.; Baptista, C. M. S. G. Continuous adiabatic industrial benzene nitration in mixed acid at a pilot plant scale, manuscript in preparation.

(24) Rodgers, M. J .; Swinton, P. F. I solation of el ectrochemically generated dinitrogen pentoxide in a pure form and its use in aromatic nitrations. In Nitration: Recent Laboratorial and Industrial Developments; Carr, R. V., Schmitt, R. J ., Albright, L. F., Eds.; ACS Symposium Series; American Chemical Society: Washington, DC, 1996; pp 58-67.

(25) Devendorf, T. E.; Stacy, J . R. Pilot-plant-scale continuous manufacturing of solid dinitrogen pentoxide. In Nitration: Recent Laboratorial and Industrial Developments; Carr, R. V., Schmitt, R. J ., Albright, L. F., Eds.; ACS Symposium Series; American Chemical Society: Washington, DC, 1996; pp 68-77.

(26) Chapman, R. D.; Smith, G. D. Separation of dinitrogen pentoxide from its solutions in nitric acid. In Nitration: Recent Laboratorial and Industrial Developments; Carr, R. V., Schmitt, R. J ., Albright, L. F., Eds.; ACS Symposium Series; American Chemical Society: Washington, DC, 1996; pp 78-96.

(27) Quadros, P. A.; Baptista, C. M. S. G. Effective interfacial area in agitated liquid-liquid continuous reactors. Chem. Eng. Sci. 2003, 58 (17), 3935-3945.

Received for review November 21, 2003 Revised manuscript received May 12, 2004 Accepted May 13, 2004

IE0342630 